Acta Crystallographica Section F

Structural Biology

and Crystallization

Communications

ISSN 1744-3091

\section{Shin Kawano, ${ }^{a} \ddagger$ Yoshiaki Yasutake, ${ }^{b}$ Kenji Tajima, ${ }^{a}$ Yasuharu Satoh, ${ }^{a}$ Min Yao, ${ }^{b *}$ Isao Tanaka ${ }^{b}$ and Masanobu Munekata ${ }^{\mathrm{a}}$}

${ }^{a}$ Division of Molecular Chemistry, Graduate School of Engineering, Hokkaido University, Kita-13, Nishi-8, Kita-ku, Sapporo, Hokkaido 060-8628, Japan, and ${ }^{\mathbf{b}}$ Division of Biological Sciences, Graduate School of Science, Hokkaido University, Kita-10, Nishi-8, Kita-ku, Sapporo, Hokkaido 060-0810, Japan

‡ Current address: Bioinformatics Center, Institute for Chemical Research, Kyoto University, Gokasho, Uji, Kyoto 611-0011, Japan.

Correspondence e-mail: yao@castor.sci.hokudai.ac.jp

Received 10 November 2004 Accepted 20 January 2005 Online 1 February 2005

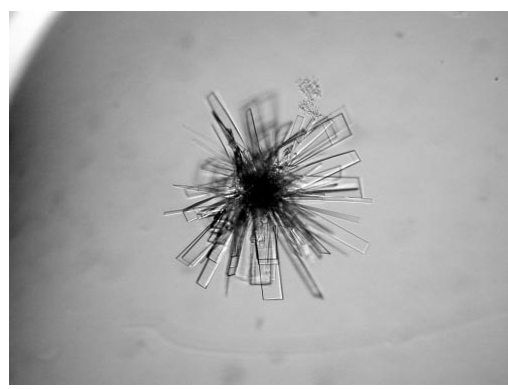

(C) 2005 International Union of Crystallography All rights reserved

\section{Crystallization and preliminary crystallographic analysis of the cellulose biosynthesis-related protein CMCax from Acetobacter xylinum}

The cellulose biosynthesis-related protein CMCax from Acetobacter xylinum was overexpressed in Escherichia coli, purified and crystallized. Single crystals of selenomethionine (SeMet) substituted CMCax were obtained by the hangingdrop vapour-diffusion method at $293 \mathrm{~K}$, primarily using polyethylene glycol 4000 as a precipitant. The crystals belong to the primitive hexagonal space group $P 6_{1}$ or $P 6_{5}$, with unit-cell parameters $a=b=89.1, c=94.2 \AA$. The predicted Matthews coefficient $\left(V_{\mathrm{M}}\right)$ value is $3.0 \AA^{3} \mathrm{Da}^{-1}$ for one CMCax monomer in the asymmetric unit. A single-wavelength anomalous dispersion (SAD) data set was collected to a resolution of $2.3 \AA$ using synchrotron radiation.

\section{Introduction}

Cellulose, which is produced by plants, algae and some bacteria, is the most abundant biopolymer on earth. Although cellulose is used in the production of many commercial materials, including papers, clothes and food additives, relatively little is known about the mechanism of cellulose biosynthesis. The Gram-negative bacterium Acetobacter xylinum has been studied as a model organism for cellulose biosynthesis, as this bacterium produces a cellulose pellicle called bacterial cellulose (BC) in culture medium. A. xylinum has a cellulose synthase operon ( $A x C e s$ operon) consisting of three or four genes (Wong et al., 1990; Saxena et al., 1994; Nakai et al., 1998; Kawano, Tajima, Uemori et al., 2002). In addition, two genes, cmcax and ccpAx, are located in the upstream region of the operon (Standal et al., 1994). The cmcax gene encodes a protein (CMCax) that exhibits cellulosehydrolyzing activity (endo- $\beta$-1,4-glucanase activity), while the enzyme has been shown to be involved in BC production (Tonouchi et al., 1995; Koo et al., 1998; Kawano, Tajima, Kono et al., 2002). Nevertheless, the actual role of CMCax in cellulose biosynthesis remains unknown.

CMCax consists of 342 amino-acid residues, including a signal peptide segment (1-20), and has a mature molecular weight of $35.6 \mathrm{kDa}$. The number of residues of cello-oligosaccharide required for recognition by this enzyme is five or more and the stereochemical course of hydrolysis is of the inverting type (Kawano, Tajima, Kono et al., 2002). CMCax is a member of glycoside hydrolase family 8 (GH8; http://afmb.cnrs-mrs.fr/CAZY/index.html; Henrissat \& Bairoch, 1996) and several crystal structures of enzymes belonging to GH8 have been determined to date (Alzari et al., 1996; Guerin et al., 2002; Van Petegem et al., 2003; Adachi et al., 2004). However, none of the enzymes reported is related to cellulose biosynthesis. To understand the structure-function relationships of CMCax, which is involved in both cellulose hydrolysis and synthesis, we have undertaken crystallographic studies. Here, we report the expression in Escherichia coli, crystallization and preliminary crystallographic characterization of CMCax.

\section{Materials and methods}

\subsection{Protein expression and purification}

The endo- $\beta$-1,4-glucanase (CMCax) gene was cloned from A. xylinum ATCC 23769 and expressed in Escherichia coli as described previously (Kawano, Tajima, Kono et al., 2002). The 
recombinant CMCax had a histidine tag at its $\mathrm{N}$-terminus in place of the signal peptide and E. coli B834 Codon Plus (DE3)-IRL (Stratagene) with pREP4 (QIAGEN) was used as the host for overproduction of SeMet-labelled CMCax. The cells were grown at $310 \mathrm{~K}$ in methionine-free medium containing $25 \mu \mathrm{g} \mathrm{ml}^{-1} \mathrm{~L}$-SeMet, $100 \mu \mathrm{g} \mathrm{ml}^{-1}$ ampicillin and $50 \mu \mathrm{g} \mathrm{ml}^{-1}$ kanamycin; isopropyl-1-thio$\beta$-D-galactopyranoside (IPTG) was added to a concentration of $1 \mathrm{~m} M$ to induce the expression of CMCax. The cells were harvested by centrifugation at $4000 \mathrm{~g}$ for $15 \mathrm{~min}$ at $277 \mathrm{~K}$ and resuspended in buffer $A$ (20 m $M$ sodium phosphate buffer $\mathrm{pH} 7.4,0.5 \mathrm{M} \mathrm{NaCl}$ and $10 \mathrm{~m} M$ imidazole). The cells were disrupted by passage through a French pressure-cell press at $8.3 \mathrm{MPa}$ and the homogenate was clarified by centrifugation at $40000 \mathrm{~g}$ for $30 \mathrm{~min}$ at $277 \mathrm{~K}$. The supernatant of the cell extract was loaded onto a Hi-Trap chelating column (Amersham Biosciences) charged with $\mathrm{NiSO}_{4}$ and equilibrated with buffer $A$. The His-tagged CMCax was then eluted with buffer $B(20 \mathrm{~m} M$ sodium phosphate buffer $\mathrm{pH} 7.4,0.5 \mathrm{M} \mathrm{NaCl}$ and $500 \mathrm{~m} M$ imidazole) and the collected enzyme fractions were applied onto a Hi-Prep 26/10 desalting column (Amersham Biosciences) equilibrated with buffer $C$ (50 $\mathrm{m} M$ sodium acetate $\mathrm{pH}$ 5.0). The fractions containing CMCax were then applied onto a $1 \mathrm{ml}$ Resource $\mathrm{S}$ cation-exchange column (Amersham Biosciences) and washed with buffer $C$. The bound proteins were eluted with a linear gradient of $0.0-1.0 \mathrm{M} \mathrm{NaCl}$. Finally, the collected fractions containing CMCax were further purified on a HiLoad 26/60 Superdex 75 pg size-exclusion column (Amersham Biosciences) equilibrated with $50 \mathrm{~m} M$ sodium phosphate buffer $\mathrm{pH}$

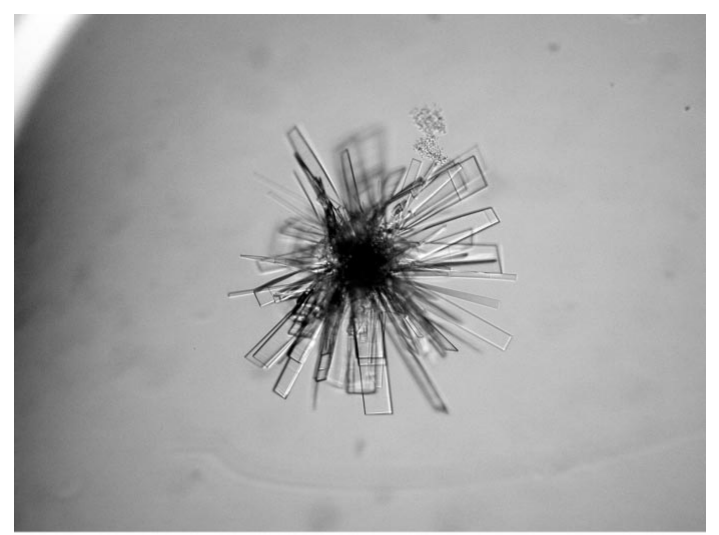

(a)

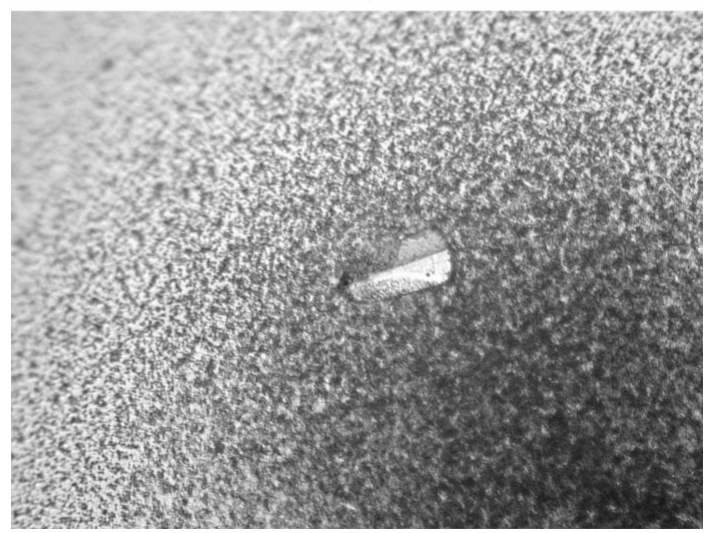

(b)

Figure 1

Crystals of CMCax. (a) The initial thin plate crystals grown in $100 \mathrm{~m} M$ sodium citrate buffer $\mathrm{pH} 5.6,30 \%(w / v)$ PEG 4000 and $200 \mathrm{~m} M$ ammonium acetate (Crystal Screen I condition No. 9). (b) The optimized thick crystal that was used for SAD data collection.
Table 1

Crystallographic parameters and Se-SAD data-collection statistics.

Values in parentheses refer to data in the highest resolution shell (2.38-2.30 $\mathrm{A})$.

\begin{tabular}{ll}
\hline Beamline & BL41XU (SPring-8) \\
Wavelength $(\AA)$ & 0.9796 \\
Resolution $(\AA)$ & $50-2.30(2.38-2.30)$ \\
Unit-cell parameters $(\AA)$ & $a=b=89.1, c=94.2$ \\
Space group & $P 6_{1}$ or $P 6_{5}$ \\
$V_{\mathrm{M}}$ value $\left(\AA^{3} \mathrm{Da}^{-1}\right)$ & $3.0(1$ molecule in the AU) \\
No. of reflections measured & 213626 \\
No. of unique reflections measured & 18850 \\
$R_{\text {sym }} \dagger$ & $0.141(0.357)$ \\
Completeness $(\%)$ & $100.0(100.0)$ \\
Redundancy & $11.3(11.4)$ \\
Mean $I / \sigma(I)$ & $20.5(6.4)$
\end{tabular}

$\dagger R_{\text {sym }}=\sum_{h} \sum_{i}\left|I_{h, i}-\left\langle I_{h}\right\rangle\right| / \sum_{h} \sum_{i} I_{h, i}$, where $\left\langle I_{h}\right\rangle$ is the mean intensity of a set of equivalent reflections.

7.0 containing $150 \mathrm{~m} M \mathrm{NaCl}$. The CMCax solution thus obtained was desalted and concentrated to approximately $4.0 \mathrm{mg} \mathrm{ml}^{-1}$ protein and frozen at $193 \mathrm{~K}$ until use.

\subsection{Crystallization}

All crystallization experiments were performed by the hangingdrop vapour-diffusion method in 24-well tissue-culture Linbro plates (ICN Biomedicals) at room temperature (291 K). Each hanging drop was formed by mixing $2 \mu \mathrm{l}$ protein solution and $2 \mu \mathrm{l}$ reservoir solution and was equilibrated against $500 \mu \mathrm{l}$ reservoir solution. The initial crystallization experiment was carried out using Crystal Screens I and II (Hampton Research) and Wizard Screen (Emerald BioStructures). We successfully obtained CMCax crystals under several conditions and further optimization of crystallization conditions was performed with variation of precipitant concentration and buffer $\mathrm{pH}$ and the use of various additives.

\subsection{X-ray diffraction study}

Prior to the diffraction experiment, the single crystals of SeMetsubstituted CMCax were rapidly soaked in solution supplemented with $20 \%(v / v)$ glycerol and flash-cooled under a nitrogen-gas stream at $100 \mathrm{~K}$. The X-ray diffraction experiment was performed on beamline BL41XU at SPring-8 (Harima, Japan). To measure the maximum $f^{\prime \prime}$ contribution from the Se atoms, the wavelength was set at $0.9796 \AA$ based on the fluorescence spectrum of the selenium $K$ absorption edge. The single-wavelength anomalous dispersion (SAD) data set was collected using a Quantum-Q315 charge-coupled device (CCD) detector (ADSC). Each oscillation frame was taken with a rotation of $1.5^{\circ}$ for $9 \mathrm{~s}$ exposure at a crystal-to-detector distance of $270 \mathrm{~mm}$ and the total rotation range for the SAD data collection was $180^{\circ}$. The measured diffraction intensities were integrated and scaled with the HKL2000 program package (Otwinowski \& Minor, 1997).

\section{Results and discussion}

The single crystals of CMCax with thin plate morphology were grown under several acidic conditions with polyethylene glycol (PEG) as a precipitant (Fig. 1a). However, the diffraction quality of these initial crystals was not suitable for the collection of complete diffraction data (data not shown). After optimization of the crystallization conditions, thick crystals with approximate dimensions of $0.1 \times 0.05$ $\times 0.05 \mathrm{~mm}$ were obtained within one month using a reservoir solution containing $100 \mathrm{~m} M$ sodium citrate buffer $\mathrm{pH} 4.4,15 \%(w / v)$ PEG 4000, 3\%(w/v) PEG 8000 and $20 \mathrm{~m} M$ ammonium sulfate (Fig. 1b). 
The crystal diffracted to a resolution of $2.3 \AA$ and was found to belong to the primitive hexagonal system, with unit-cell parameters $a=b=89.1, c=94.2 \AA$. The calculated $R_{\text {sym }}$ value and the reflection conditions for $00 l$ indicated that the space group of the crystal must be $P 6_{1}$ or $P 6_{5}$. Assuming the presence of one CMCax monomer in the asymmetric unit, a Matthews coefficient ( $V_{\mathrm{M}}$ value) of $3.0 \AA^{3} \mathrm{Da}^{-1}$ was obtained, which corresponded to a solvent content of $59.1 \%$ (Matthews, 1968). The crystallographic parameters and the SAD data-collection statistics are summarized in Table 1. SAD phasing is currently in progress.

The authors would like to thank R. Ogawa and Y. Inoue of the Graduate School of Science at Hokkaido University for their kind help with protein purification. We also thank M. Kawamoto and N. Shimizu of the Japan Synchrotron Radiation Research Institute (JASRI) for their kind assistance with X-ray diffraction data collection on beamline BL41XU at SPring-8. This work was supported by a research grant from the National Project on Protein Structural and Functional Analyses and a Grant-in-Aid for Scientific Research (No. 14750688) from the Ministry of Education, Culture, Sports, Science and Technology of Japan. Financial support was also provided by the Akiyama Foundation and Hokkaido University Clark Memorial Foundation.

\section{References}

Adachi, W., Sakihama, Y., Shimizu, S., Sunami, T., Fukazawa, T., Suzuki, M., Yatsunami, R., Nakamura, S. \& Takenaka, A. (2004). J. Mol. Biol. 343, 785795.

Alzari, P. M., Souchon, H. \& Dominguez, R. (1996). Structure, 4, 265-274.

Guerin, D. M., Lascombe, M. B., Costabel, M., Souchon, H., Lamzin, V., Beguin, P. \& Alzari, P. M. (2002). J. Mol. Biol. 316, 1061-1069.

Henrissat, B. \& Bairoch, A. (1996). Biochem. J. 316, 695-696.

Kawano, S., Tajima, K., Kono, H., Erata, T., Munekata, M. \& Takai, M. (2002). J. Biosci. Bioeng. 94, 275-281.

Kawano, S., Tajima, K., Uemori, Y., Yamashita H., Erata, T., Munekata, M. \& Takai, M. (2002). DNA Res. 9, 149-156.

Koo, H. M., Song, S. H., Pyun, Y. R. \& Kim, Y. S. (1998). Biosci. Biotechnol. Biochem. 62, 2257-2259.

Matthews, B. W. (1968). J. Mol. Biol. 33, 491-497.

Nakai, T., Moriyama, A., Tonouchi, N., Tsuchida, T., Yoshinaga, F., Horinouchi, S., Sone, Y., Mori, H., Sakai, F. \& Hayashi, T. (1998). Gene, 213, 93-100.

Otwinowski, Z. \& Minor,W. (1997). Methods Enzymol. 276, 307-326.

Saxena, I. M., Kudlicka, K., Okuda, K. \& Brown, R. M. Jr (1994). J. Bacteriol. 176, 5735-5752.

Standal, R., Iversen, T. G., Coucheron, D. H., Fjaervik, E., Blatny, J. M. \& Valla, S. (1994). J. Bacteriol. 176, 665-672.

Tonouchi, N., Tahara, N., Tsuchida, T., Yoshinaga, F., Beppu, T. \& Horinouchi, S. (1995). Biosci. Biotechnol. Biochem. 59, 805-808.

Van Petegem, F., Collins, T., Meuwis, M. A., Gerday, C., Feller, G. \& Van Beeumen, J. (2003). J. Biol. Chem. 278, 7531-7539.

Wong, H. C., Fear, A. L., Calhoon, R. D., Eichinger, G. H., Mayer, R., Amikam, D., Benziman, M., Gelfand, D. H., Meade, J. H. \& Emerick, A. W. (1990). Proc. Natl Acad. Sci. USA, 87, 8130-8134. 